\title{
PENGARUH METODE COGNITIVE BEHAVIOUR TREATMENT APPLIED BEHAVIOUR ANALYSIS (CBT ABA) TERHADAP KEPATUHAN ANAK BERKEBUTUHAN KHUSUS DI KLINIK YAMET YOGYAKARTA
}

\author{
Erna Ariyanti K \\ Politeknik Kesehatan Surakarta Jurusan Okupasi Terapi
}

\begin{abstract}
Special Need Children, Applied Behavior Approach, Comformity. Recently, special need children are the most common issue, event somepeople hiding this reality for some reason. It will be a negative impact for all special need children in this country. Special need children being withdrawl and they will depent to other people surround. Instead of that, it's necesarry to develop an integrated service for special need children to enhanced their skills as independent human being. So they can participate as other people does. Occupational therapist have an important role to help them and improved their independency. The purpose of this research is to know the impact of applied behavior analysis through special need children's comformity in Yamet Children Private Pratice Yogyakarta. Desain of this research is one-grouppretest-posttest design. This research has a total sampling methode. Result of this research : there is an impact of applied behavior analysis technique through special need children comformity Yamet Yogyakarta.
\end{abstract}

Keyword : Special Need Children, Applied Behavior Approach, Comformity

Abstrak : Anak Berkebutuhan Khusus, ABA, Kepatuhan. Saat ini banyak Anak Berkebutuhan Khusus (ABK) yang keberadaannya disembunyika karena berbagai alasan. Kondisi ini berdampak buruk terhadap semua ABK di Negara ini. Sehingga mereka menarik diri dan menjadi sangat tergantung pada orang lain. Oleh karena itu perlu dikembangkan pelayanan terpadu bagi ABK untuk meningkatkan keterampilan mereka supaya dapat hidup mandiri. Sehingga mereka dapat berpartisipasi aktif seperti orang lain. Okupasi Terapis mempunyai peran penting dalam membantu dan mengembangkan kemandirian mereka. Tujuan penelitian ini adalah mengetahui pengaruh metode cognitive behaviour treatment applied behaviour analysis (cbt aba) terhadap kepatuhan anak berkebutuhan khusus di klinik Yamet Yogyakarta. Desain penelitian ini adalah one-group-pretest-posttest design dengan total sampling. Hasil penelitian ada pengaruh metode cognitive behaviour treatment applied behaviour analysis (cbt aba) terhadap kepatuhan anak berkebutuhan khusus di klinik Yamet Yogyakarta.

Kata Kunci : Anak Berkebutuhan Khusus, ABA, Kepatuhan

\section{PENDAHULUAN}

Anak berkebutuhan khusus dengan

segala keterbatasannya sangat

membutuhkan perhatian dan bantuan untuk mencapai kemandirian. Salah satu tahap yang penting dalam mencapai kemandirian ABK adalah kepatuhan dalam mengikuti proses terapi. Anak 
dengan keterbatasan dalam komunikasi sangat memerlukan kepatuhan untuk membangun komunikasi dengan dunia luar terutama dengan orang disekitarnya. Anak dengan autis, hiperaktif, cerebral palsy dan gangguan perkembangan lainnya memerlukan keterampilan berkomunikasi verbal yang baik sehingga mereka dapat berperilaku dan merespon setiap informasi dengan baik dan benar (Yayasan Autisma Indonesia, 1998).

Menurut Yayasan Autisma Indonesia (1998) metode ABA merupakan salah satu metode yang dapat membantu anak berinteraksi dan berkomunikasi dengan orang lain sehingga mereka dapat mencapai kemandirian. Program ini terdiri dari berbagai tahapan yang nantinya akan menghasilkan suatu respon perilaku yang adaptif. Perilaku adaptif ini sangat penting dan perlu untuk mempelajari berbagai macam keterampilan dalam kehidupan sehari-hari.

Okupasi terapi merupakan tenaga kesehatan yang sangat berperan dalam membantu kemandirian anak dalam aktifitas produktifitas, aktifitas kehidupan sehari-hari dan aktifitas leisure atau pemanfaatan waktu luang. Berdasarkan hal tersebut di atas, maka okupasi terapis mempunyai peran yang sangat penting dalam membantu anak berkebutuhan khusus dalam mencapai kemandirian melalui kepatuhan. Sehingga peneliti tertarik untuk mengetahui pengaruh metode ABA terhadap kepatuhan anak berkebutuhan khusus.

Penelitian ini dilakukan untuk mengetahui "Apakah ada pengaruh metode applied behaviour analysis (ABA) terhadap kepatuhan anak berkebutuhan khusus di Klinik Yamet Yogyakarta? Sedangkan tujuan umum penelitian ini adalah untuk mengetahui pengaruh metode applied behaviour analysis ( ABA) terhadap kepatuhan anak berkebutuhan khusus di Klinik Yamet Yogyakarta. Secara khusus penelitian ini juga bertujuan untuk mengetahui data demografi pasien yang meliputi jenis kelamin, kondisi atau diagnosis klien di Klinik Yamet Yogyakarta; mengetahui perubahan atau perkembangan yang terjadi terkait dengan kepatuhan anak berkebutuhan khusus setelah mendapatkan layanan terapi dengan metode ABA di klinik Yamet Yogyakarta.

Anak berkebutuhan khusus merupakan anak-anak yang mengalami gangguan fisik, mental, sosial, dan emosional yang sudah terdeteksi pada masa kehamilan hingga usia dini tumbuh kembang yang mengalami keterbatasan atau keluarbiasaan baik fisik, mentalintelektual, sosial maupun emosional yang berpengaruh secara signifikan dalam proses pertumbuhan dan perkembangan sesuai anak seusianya (Harnowo, 2013; Kementerian Pemberdayaan Perempuan dan Perlindungan Anak, 2013).

Berbagai upaya dilakukan untuk membantu kemandirian anak berkebutuhan khusus. Terapi perilaku merupakan suatu teknik terapi yang bertujuan untuk menghilangkan perilakuperilaku yang tidak dapat diterima secara sosial dan untuk membangun perilakuperilaku yang tidak dapat diterima secara sosial dan untuk membangun perilakuperilaku yang baru secara sosial bermanfaat dan dapat diterima, yang berguna untuk mengurangi perilaku yang tidak lazim dan menggantikan dengan perilaku yang bisa diterima masyarakat (Sunu yang ditulis kembali oleh Oktavia et al ,2014; Yuwono dalam Oktavia et al ,2014).Yuwono dalam Oktavia et al (2014) menyatakan bahwa intervensi dini 
anak autism menekankan kepatuhan, keterampilan anak dalam meniru dan membangun kontak mata. Handojo dalam Oktavia et al (2014) menyatakan bahwa metode ABA digunakan untuk meningkatkan perilaku yang positif, fokus metode ini dalam penanganan terletak pada pemberian penguatan yang positif setiap kali anak merespon instruksi sehingga perilaku yang positif dalam diri anak menjadi sebuah pembiasaan yang buruk.

Berbagai metode yang digunakan dalam mengangani anak berkebutuhan khusus yang dapat diterapkan baik di klinik, sekolah maupun pusat terapi ABK antara lain : Applied Behavior Analysis $(A B A)$, Metode Son-Rise, metode Kauffman, Menurut Merry (2008) metode ABA dikembangkan berdasarkan teori Skinner yang menyatakan bahwa pengendalian perilaku anak dapat dilakukan dengan cara memanipulasi imbalan dan hukuman (reinforcement dan punishment). Metode ini paling banyak digunakan sebagai salah satu cara memperbaiki perilaku terutama pada anak dengan autism. Metode ini menggunakan teknik one on one atau satu terapis untuk satu penyandang autism.

Tujuan metode ABA adalah adanya perubahan perilaku yang diperoleh dengan memodifikasi perilaku dan menggunakan sistem umpan balik pada saat anak melakukan perilaku yang diharapkan. Metode ini lebih menuntut kepatuhan anak terhadap serangkaian aktivitas yang tertuang dalam kurikulum ABA. Sehingga dapat tercapai tujuan ABA yaitu : anak mampu melakukan komunikasi dua arah secara aktif, mampu sosialisasi ke dalam lingkungan yang umum, mengurangi atau menghilangkan perilaku maladaptif, serta mampu melakukan aktivitas bina diri dan keterampilan lainnya. Dalam pelaksanaannya, metode Loovas ini mempunyai kurikulum yang didesain untuk anak penyandang autism yang berusia $2-5$ tahun dengan minimal terapi 40 jam dalam seminggu dengan aturan yang disiplin dan program dilakukan secara berkelanjutan (Merry, 2008). Beberapa teknik yang termasuk dalam ABA adalah sebagia berikut: Shaping, Task Analysis ,Chaining , Reinforcement, Fading, Discrete Trial Redirection, Prompting , Ignoring (Ekalitani, 2015).

Kepatuhan merupakan komponen penting dalam metode ABA, karena metode ini menuntut kepatuhan anak untuk dapat mengikuti proses terapi dengan metode ABA. Menurut Suparyanto (2010) kepatuhan merupakan perilaku positif dalam mencapai tujuan terapi, menurut perintah atau aturan. Menurut Kelman yang dikutip oleh Suparyanto (2010) perubahan sikap dan perilaku individu dimulai dengan tahap kepatuhan, identifikasi kemudian baru menjadi internalisasi. Mula-mula individu mematuhi anjuran atau instruksi tanpa kerelaan untuk melakukannya dan seringkali hal ini dilakukan karena ingin menghindari hukuman atau sanksi jika tidak patuh atau mendapatkan imbalan yang dijanjikan jika mematuhi anjuran/ aturan tersebut, tahap ini disebut tahap kesediaan.

Yuwono dalam Hardiani \& Rahmawati (2012) menyatakan bahwa dasar dari metode ABA menggunakan teori perilaku yang menekankan kepatuhan pada tahap awal kemudian keterampilan anak dalam meniru dan membangun kontak mata. Konsep kepatuhan ini sangat penting agar mereka dapat mengubah perilaku dan dapat 
melakukan interaksi sosial. Faktor-faktor yang mempengaruhi kepatuhan adalah sebagai berikut: pemahaman tentang instruksi, tingkat pendidikan, kesakitan dan pengobatan, keyakinan, sikap dan kepribadian, dukungan keluarga, tingkat ekonomi, dukungan sosial, perilaku sehat dan dukungan profesi kesehatan. Kepatuhan juga dipengaruhi oleh demografi seperti usia, jenis kelamin, suku bangsa, status sosio ekonomi dan pendidikan; penyakit seperti tingkat keparahan penyakit dan hilangnya gejala akibat terapi; program terapeutik seperti kompleksitas program dan efek samping yang tidak menyenangkan; faktor psikososial seperti intelegensia, sikap terhadap tenaga kesehatan, penerimaan, atau penyangkalan terhadap penyakit, keyakinan agama atau budaya dan biaya /kemampuan finansial (Carpenito yang ditulis kembali oleh Suparyanto, 2010; Suddart \& Brunner yang dikutip oleh Wahdi, 2012)

Adapun faktor-faktor yang mempengaruhi ketidakpatuhan menurut Niven yang dikutip oleh Wahdi (2012) ada empat yaitu 1). Pemahaman tentang instruksi dimana individu tidak akan mampu mematuhi instruksi apabila individu tersebut salah dalam memahami instruksi yang diberikan kepadanya. 2). Kualitas interaksi. Kualitas interaksi antara profesional kesehatan dan pasien merupakan bagian yang penting dalam menentukan derajat kepatuhan. 3). Isolasi sosial dan keluarga. Keluarga merupakan faktor penting yang sangat berpengaruh dalam menentukan keyakinan dan nilai kesehatan individu serta dapat menentukan program pengobatan/terapi yang dapat mereka terima. 4). Keyakinan, sikap dan kepribadian.
Metode ABA merupakan salah satu metode yang sangat terkenal dan banyak digunakan untuk memperbaiki perilaku anak yang maladaptif. Menurut Handojo yang ditulis kembali oleh Oktavia et al (2014) metode ABA sangat terstruktur sehingga mudah diajarkan kepada terapis yang menangani ABK seperti autism. Dalam penelitiannya Oktavia et al (2014) menyatakan bahwa dengan metode ABA kemandirian anak autism meningkat setelah mendapatkan terapi dengan metode ABA ini. Kemandirian anak dalam yang diukur dalam penelitian ini merupakan kemandirian yang dimulai dari perubahan perilaku sebelum anak masuk kelas sehingga perilaku anak di sekolah yang menjadi positif. Kepatuhan dalam metode ABA diukur dengan sebuah pemeriksaan khusus. Data hasil pemeriksaan tersebut merupakan data nominal, dimana kemampuan atau perilaku yang diamati atau diukur diberikan nilai 1 dan 2 . Hipotesis penelitian ini adalah ada pengaruh metode applied behaviour analysis $(A B A)$ terhadap kepatuhan anak berkebutuhan khusus di Klinik Yamet Yogyakarta.

\section{METODE PENELITIAN}

Penelitian ini merupakan penelitian quasi eksperimental kuantitatif. Penelitian dirancang dengan desain one group pretest posttest design. Penelitian dilakukan dengan memberikan intervensi pada sampel dengan metode Applied Behavior Analysis (ABA). Populasi penelitian ini adalah pasien atau anak berkebutuhan khusus di Klinik Yamet Yogyakarta. Sedangkan teknik pengambilan sampel dilakukan dengan cara totally sampling, sehingga sampel penelitian ini adalah semua anak 
berkebutuhan khusus di KlinikYamet Yogyakarta. Cara pengumpulan data dalam penelitian ini dilakukan dengan pemeriksaan kepatuhan anak dengan instrumen pemeriksaan yang ada dalam buku pedoman Applied Behavior Analysis (ABA). Data dalam penelitian ini berupa data nominal dan dilakukan di awal dan di akhir intervensi. Instrumen penelitian yang digunakan dalam penelitian ini berupa blangko pemeriksaan kepatuhan anak pada metode Applied Behavior Analysis (ABA). Uji statistik yang digunakan adalah uji Wilcoxon karena sebaran data tidak normal dengan nilai signifikansi yang digunakan dalam penelitian ini adalah 5\%.

\section{HASIL PENELITIAN}

Klinik Yamet Yogyakarta memiliki berbagai layanan terapi termasuk terapi perilaku dengan metode Applied Behavior Analysis (ABA). Jumlah pasien di klinik tersebut sampai bulan Juli 2015 adalah 20 orang anak berkebutuhan khusus dengan berbagai macam kondisi seperti Autism, Cerebral Palsy, Intellectual Disability, Sensory Integration Disorder,Pervasive Developmental Disorder,Learning Disorder, Hyperactive, Down Syndrome.

Gambaran demografi responden penelitian ini menurut jenis kelamin dapat dilihat pada table 1 berikut:

Tabel 1

Gambaran Demografi Responden Penelitian

\begin{tabular}{llll}
\hline No & Jenis & Frekuensi & Prosentase \\
& Kelamin & & \\
\hline 1 & Laki - laki & 14 & $70 \%$ \\
2 & Perempuan & 6 & $30 \%$ \\
\hline & Total & 20 & \\
\hline
\end{tabular}

Sedangkan berdasarkan kondisi diagnosis responden penellitian ini dapat dilihat pada tabel 2 berikut :

\section{Tabel 2}

Gambaran Kondisi Diagnosis Responden

\begin{tabular}{llll}
\hline No & $\begin{array}{l}\text { Kondisi/diagnosis } \\
\text { Responden }\end{array}$ & Frekuensi & Prosentase \\
\hline 1 & $\begin{array}{l}\text { Pervaside } \\
\text { Developmental } \\
\text { Disorder }\end{array}$ & 4 & $20 \%$ \\
2 & $\begin{array}{l}\text { Autism } \\
3\end{array}$ & 10 & $50 \%$ \\
& $\begin{array}{l}\text { Learning } \\
\text { Disability }\end{array}$ & 1 & $5 \%$ \\
5 & Down Syndrome & 1 & $5 \%$ \\
& $\begin{array}{l}\text { Sensory } \\
\text { Integration }\end{array}$ & 1 & $5 \%$ \\
6 & $\begin{array}{l}\text { Disorder } \\
\text { Speech Delay }\end{array}$ & 1 & $5 \%$ \\
7 & $\begin{array}{l}\text { Intellectual } \\
\text { Disability }\end{array}$ & 2 & $10 \%$ \\
Total & 20 & \\
\hline
\end{tabular}

Hasil uji statistik non parametrik

Wilcoxon menunjukkan bahwa tidak ada responden pada pretes yang mempunyai nilai kepatuhan lebih rendah dari pada posttest. Kemudian semua responden (dua puluh responden) mengalami peningkatan kepatuhan dan tidak ada satu respondenpun yang mempunyai nilai kepatuhan yang sama sebelum dan setelah diberikan intervensi. Sedangkan berdasarkan hasil uji statistik dengan Uji Wilcoxon diperoleh hasil bahwa nilai signifikansinya adalah $0,000(\mathrm{p}<0,05)$. Sehingga dapat disimpulkan bahwa terdapat pengaruh metode ABA terhadap kepatuhan ABK di Klinik Yamet Yogyakarta.

\section{PEMBAHASAN}

Berdasarkan hasil penelitian ini dapat disimpulkan bahwa terdapat pengaruh yang signifikan terapi dengan metode ABA terhadap kepatuhan ABK di klinik Yamet Yogyakarta. Hal ini juga 
sesuai dengan pendapat Merry (2008) yang menyatakan bahwa metode ini paling banyak digunakan sebagai salah satu cara memperbaiki perilaku terutama pada anak dengan autism.

Begitu juga dengan Yuwono dalam Oktavia et al (2014) menyatakan bahwa intervensi dini anak autism menekankan kepatuhan, keterampilan anak dalam meniru dan membangun kontak mata. Handojo dalam Oktavia et al (2014) menyatakan bahwa metode ABA digunakan untuk meningkatkan perilaku yang positif, fokus metode ini dalam penanganan terletak pada pemberian penguatan yang positif setiap kali anak merespon instruksi sehingga perilaku yang positif dalam diri anak menjadi sebuah pembiasaan yang buruk.

Selain itu beberapa penelitian juga mendukung hasil penelitian ini, yaitu : Oktavia et al (2014) menyatakan bahwa dengan metode $\mathrm{ABA}$ kemandirian anak autism meningkat setelah mendapatkan terapi dengan metode ABA ini. Yuwono dalam Hardiani \& Rahmawati (2012) menyatakan bahwa dasar dari metode ABA menggunakan teori perilaku yang menekankan kepatuhan pada tahap awal kemudian keterampilan anak dalam meniru dan membangun kontak mata. Konsep kepatuhan ini sangat penting agar meraka dapat mengubah perilaku dan dapat melakukan interaksi sosial. Implikasi dari penelitian ini adalah bahwa metode ABA menjadi penting dalam perubahan perilaku ABK khususnya anak dengan autism.

\section{KESIMPULAN DAN SARAN}

Penelitian ini dapat disimpulkan bahwa terdapat pengaruh metode applied behaviour analysis (ABA) terhadap kepatuhan anak berkebutuhan khusus di Klinik Yamet Yogyakarta. Berdasarkan jenis kelamin diketahui bahwa responden didominasi oleh klien dengan jenis kelamin laki-laki. Sedangkan responden terbanyak dalam penelitian ini mempunyai kondisi atau diagnosis autism. Sehubungan dengan hal tersebut dapat disimpulkan bahwa metode applied behaviour analysis (ABA) mempunyai peran yang sangat besar dalam meningkatkan kepatuhan anak berkebutuhan khusus terutama anak yang memiliki gangguan perilaku. Penelitian ini masih banyak kekurangan terutama dalam jumlah sampel atau responden, sehingga bagi penelitian mendatang akan lebih baik bila populasi penelitian ditambah dan diperluas agar hasilnya dapat digeneralisasikan pada populasi lain dan bermanfaat bagi masyarakat luas. Disamping itu juga harus lebih detail dalam pemilihan sampel atau lebih terperinci dalam menentukan kriteria sampel sehingga hasilnya akan lebih spesifik dan analisis lebih tajam.

\section{DAFTAR RUJUKAN}

Bendi. D.( 2006). Pendidikan Anak Berkebutuhan Khusus. Jakarta: Rineka Cipta.

Hallahan, D.P. \& Kauffman, J.M. 2006. Exceptional Learners: Introduction to Special Education 10th ed. USA: Pearson.

Hardiani, R.S., \& Rahmawati, S. (2012). Metode ABA : kemampuan bersosialisasi terhadap kemampuan interaksi sosial anak autis. Jurnal Keperawatan Soediman. (7).

Harnowo, P.A. (2013). Jumlah anak berkebutuhan khusus di Indonesia diperkirakan 4,2 juta. Detikhealth.

Kementerian Pemberdayaan Perempuan \& Perlindungan Anak Republik 
Indonesia (2013). Panduan penanganan anak berkebutuhan khusus bagi pendamping (orang tua, keluarga dan masyarakat). Jakarta.

Merry (2008). Studi desain interior pusat terapi anak berkebutuhan khusus pada sekolah Safir Surabaya. Dimensi Interior (1).35-49.

Oktaviana, A., Syamsudin, M.M., \& Atmojo, I. R. W. (2014). Efek terapi perilaku dengan metode applied behavior analysis terhadap kemandirian anak autism. Skripsi. Surakarta: UNS. 